\title{
Critical Illness Myopathy
}

National Cancer Institute

\section{Source}

National Cancer Institute. Critical IIIness Myopathy. NCI Thesaurus. Code C122793.

Acute muscle weakness and paralysis that develops in critically ill patients who have been treated with multiple drugs during their intensive care unit stay. It is associated with delayed weaning from mechanical ventilation and prolonged rehabilitation. 